\section{Aversion of conspecific odor of frustrative nonreward in rats*}

\author{
IRA COLLERAIN† and H. W. LUDVIGSON†† \\ Texas Christian University, Fort Worth, Tex. 76129
}

Laboratory rats avoided the arm of a $T$-maze in which other rats had previously experienced frustrative nonreward, i.e., nonreward in the presence of cues associated with reward, thus supporting the proposition that frustrated rats excrete an odor mildly aversive to conspecifics. They displayed indifference toward arms in which rats had been rewarded or merely placed without treatment.

Recently, attention has been directed toward the study of odors which appear to be excreted by laboratory rats when given common experimental treatments. For example, the existence of a difference in odor following the receipt of reward as against frustrative nonreward (herein termed "nonreward") (Amsel, Hug, \& Surridge, 1969; Ludvigson, 1969; Ludvigson \& Sytsma, 1967; McHose, 1967; McHose, Jacoby, \& Meyer, 1967; Seago, Ludvigson, \& Remley, 1970) and, more specifically, the existence of an odor associated with nonreward (Morrison \& Ludvigson, 1970; Pratt \& Ludvigson, 1970) seem established.

One unanswered question about such odors is whether they are inherently "attractive" or "aversive" for the rat. Although several studies are consistent with the view that nonrewarded rats excrete an aversive "frustration odor" (McHose \& Ludvigson, 1966; Pratt \& Ludvigson, 1970; Wasserman \& Jensen, 1969), other interpretations appealing to exploratory responses or novel stimulation are possible. The present studies investigated this problem by assessing the tendency of rats, in the apparent absence of reinforcement, to approach or avoid any odor resulting from reward, nonreward, or a "neutral" treatment.

In the first study, odorant Ss (Group O) were given rewarded or nonrewarded placements in a goalbox of a T-maze. Experimental animals (Group E) were given free-choice test trials with either "odor of reward" or "odor of nonreward" in one goalbox and no odor (clean floor and walls) in the other. The second study replicated the first and also provided a test of preference for odor from neutrally

*Supported in part by PHS Grant MH13314.

†Now at LaGrange College, LaGrange, Ga. 30240 .

† Reprints may be obtained from $\mathrm{H}$. W. Ludvigson, Department of Psychology, Texas Christian University, Ft. Worth, Tex. 76129. treated rats. Ss in a second experimental group (Group En) were given a free choice of a clean goalbox or a box in which a second group of odorant Ss (Group On) had been given neutral placements. The placements were neutral in that these odorant Ss never received reward in the maze or at any locus outside the home cage.

\section{SUBJECTS}

The Ss were experimentally naive male albino rats. At the outset of the experiment, they were 180 days old and 110 days old in Experiments 1 and 2 , respectively. Throughout the experiment, they were maintained on $11 \mathrm{~g}$ of Purina Lab Chow per day. The numbers of $\mathrm{Ss}$ in the various groups were: 15 and 10 in Groups $O$ and $E$, respectively, of Experiment 1, and 15, 15,9 , and 9 in Groups $O$, On, E, and En, respectively, of Experiment 2.

\section{APPARATUS}

The apparatus, described previously (Morrison \& Ludvigson, 1970), had a roll of brown Scott paper toweling affixed to the right of the startbox. This paper was threaded around the walls and could be pulled through, thus providing a clean surface for the interior maze walls. A clean floor surface could also be provided by sliding kraft paper from a continuous roll under the alley.

Gentling of Ss and habituation to each experiment. Experimental Ss were placed in the apparatus and permitted free exploration for 5 min on each day. Odorant Ss explored one of the goalboxes on one day and the other on the second day. To acquaint them with the reward, the odorant Ss received 10 of the $37 \cdot \mathrm{mg}$ Noyes reward pellets in their home cages on these days.

Training began on Day 10 and lasted for 9 days in Experiment 1 and 16 days in Experiment 2. Odor of reward was provided for experimental Ss by successive rewarded placements of three hungry $(22 \mathrm{~h}$ food deprived) $\mathrm{Ss}$ from Group $O$ into one of the goalboxes of the maze. A rewarded

\section{PROCEDURE} the apparatus occurred on Days 8-9 of. placement consisted of $30 \mathrm{sec}$ of free access to food pellets in a circular foodcup. Odor of nonreward was obtained by successive placements of three Ss from Group $O$ into one of the goalboxes containing an empty foodcup. Confinement duration was also $30 \mathrm{sec}$ for these nonrewarded placements. Similarly, in the second experiment, neutral odor was achieved by successive placements of three Ss from Group On into an empty goalbox. Unlike Group O, Group On never received food in the maze. The interval between successive placements and between the third placement and a subsequent test trial for an experimental $S$ was approximately 10 sec. Nothing was done to the maze between the placements and the test trial, except that the foodcup and any visible food crumbs were removed. Following its choice, an experimental $S$ was confined in the empty, chosen goalbox for $10 \mathrm{sec}$. After each test trial, clean paper was placed in the maze before three more placements were administered.

In Experiment 1, Ss in Group 0 were given a repeated double-alternation pattern of rewarded and nonrewarded placements (RRNNRRNN) on each day of training. Members of Group E, given four choices per day, were alternately required to choose between "odor of reward" or a clean box and "odor of nonreward" or a clean box. This was accomplished by rotating through the odorant Ss and giving interspersed test trials to experimental Ss after every third placement (see Table 1). Ss were run in a constant order throughout the study so that the same odorant Ss always provided odor for a given experimental $S$. As illustrated in Table 1 , the position of a placement in the left or right goalbox was varied according to irregular sequences designed by Fellows (1967) to eliminate biasing influences of position responses and other tendencies on measures of preference. Different irregular sequences were applied for different experimental Ss.

Experiment 2 was similar to Experiment 1, except that the schedule of rewarded and nonrewarded placements for Group $O$ was irregular instead of being in a double-alternation pattern, specifically, RNNRRRNN, NRRNNNRR, and RNRNNRNR, over a 3-day cycle. As a consequence, choices for Group E occurred according to the schedules: RNRN, NRNR, RRNN for half the Ss and NRRN, RNNR, NNRR for half the Ss, where $R$ and $N$ refer to a choice of odor of reward vs clean and odor of nonreward vs clean, respectively. Group On also received eight 
Table 1

Daily Schedule of Rewarded (R) and Nonrewarded (N) Placements for Ss in Group $O$ and Test Trials $\left(T_{\mathfrak{j}}\right)$ for the $i^{\text {th }} S$ in Group $E$ in Experiment 1*

\begin{tabular}{|c|c|c|c|c|c|c|c|c|c|}
\hline $\begin{array}{l}\text { Odorant } \\
\text { S Number }\end{array}$ & & & & Daily & Events & & & & $\begin{array}{c}\text { Experimental } \\
\text { S Number }\end{array}$ \\
\hline 1 & Rl & $\mathbf{R r}$ & $\mathrm{Nr}$ & Nl & $\mathbf{R l}$ & $\mathbf{R l}$ & N1 & $\mathbf{N r}$ & \\
\hline 2 & Rl & $\mathrm{Rr}$ & $\mathrm{Nr}$ & Nl & Rl & $\mathbf{R} 1$ & NI & $\mathrm{Nr}$ & \\
\hline \multirow[t]{2}{*}{3} & R1 & $\mathbf{R r}$ & $\mathrm{Nr}$ & $\mathrm{Nl}$ & Rl & Rl & $\mathrm{N1}$ & $\mathrm{Nr}$ & \\
\hline & $\mathrm{T} 1$ & $\mathrm{~T} 6$ & $\mathrm{~T} 1$ & T6 & T1 & T6 & $\mathbf{T} 1$ & T6 & 1 and 6 \\
\hline 4 & $\mathbf{R r}$ & Rl & $\mathrm{N1}$ & N1 & $\mathbf{R r}$ & Rr & $\mathrm{Nr}$ & N1 & \\
\hline 5 & $\mathbf{R r}$ & RI & $\mathrm{Nl}$ & $\mathrm{N} 1$ & $\mathbf{R r}$ & $\mathbf{R r}$ & Nr & NI & \\
\hline \multirow[t]{2}{*}{6} & $\mathrm{Rr}$ & RI & $\mathrm{Nl}$ & $\mathbf{N 1}$ & $\mathbf{R r}$ & $\mathrm{Rr}$ & $\mathrm{Nr}$ & N1 & \\
\hline & $\mathrm{T} 2$ & $\mathrm{~T} 7$ & T2 & T7 & $\mathrm{T} 2$ & T7 & T2 & T7 & 2 and 7 \\
\hline 7 & (etc & & & & & & & & \\
\hline 8 & & & & & & & & & \\
\hline • & & & & & & & & & \\
\hline • & & & & & & & & & \\
\hline . & & & & & & & & & \\
\hline
\end{tabular}

*Position of the placement in the left (l) or right (r) goalbox is also illustrated for the first training day. The order of events proceeded down the first column, then down the second column, etc.

placements per day, but none with reward. Thus, all four choices per day for Ss in Group En were between neutral odor and a clean box.

$$
\text { RESULTS }
$$

Figure 1 presents the percentage of trials when Ss avoided the goalbox in which odorant Ss had been placed and entered the other arm of the maze. In both experiments, Group E displayed an early tendency to avoid the arm in which nonreward had been administered, followed by a diminution or disappearance of that tendency. In general, there was little indication of anything but a chance level of response to the arm in which rewarded or neutral placements had been given. Analyses of variance of data from Group $E$ with odor ( $R$ vs $\mathrm{N}$ ), blocks of trials, and Ss as factors revealed significant effects of odor $(F=96.0$ and $12.19 ; \mathrm{df}=1 / 9$ and $1 / 8$; $\mathrm{p}<.01)$ and blocks $(\mathrm{F}=5.47$ and $4.96 ; \mathrm{df}=2 / 18$ and $3 / 24 ; \mathrm{p}<.025$ for Experiments 1 and 2 , respectively), but no interaction. Analysis of variance of the data from Group $\mathrm{En}$ in Experiment 2 showed no evidence of an effect of blocks of trials $(F<1)$.

To assess deviation of choice from a chance $(50 \%)$ level, $t$ tests were performed on the data for each treatment on each block of trials. Avoidance of nonreward was significantly greater than chance on Blocks 1 and 2 in Experiment 1 $(t=2.32$ and $9.47 ; \mathrm{df}=9 ; \mathrm{p}<.05$ and .001 , respectively) and in Experiment $2 \quad(\mathrm{t}=3.41$ and 5.55 ; $\mathrm{df}=8 ; \mathrm{p}<.01$ and .001 , respectively). No other points deviated significantly from chance.

\section{DISCUSSION}

Frustrative nonreward, i.e., nonreward in a context in which reward has been previously encountered, has often been said to elicit an emotional reaction (e.g., Amsel, 1958). The present data suggest that frustrative nonreward also causes rats to excrete an odor which is aversive to conspecifics as defined by a spatial avoidance response. The inference that the odor is specific to frustrative nonreward and not generated by nonfrustrative nonreward is supported by the absence of aversion to neutral placements. Thus, for Experiments 1 and 2. the odor appears to be a "frustration odor" rather than merely a characteristic scent.

This latter inference must be tempered by the observation that nonrewarded placements produced some what more agitated behavior by odorant Ss than did neutral placements. If movement is directly related to amount of scent excretion, then this might account for the data. However, on this movement excretion hypothesis, neutral placements should have produced a level of avoidance greater than rewarded placements, since there was little movement during the latter. The fact that this did not occur supports the proposition that rats excrete a substance as a function of a specific class of treatments.

The size of the class of treatments is not presently known, though it probably includes delayed reward (Ludvigson, 1970), electric shock stress (Valenta \& Rigby, 1968), and perhaps reduced reward (Davis \& Ludvigson, 1969). Similarly, the nature of the substance excreted is not known. Although neither fecal matter nor urine appears to be the source of the odor, recent research from our

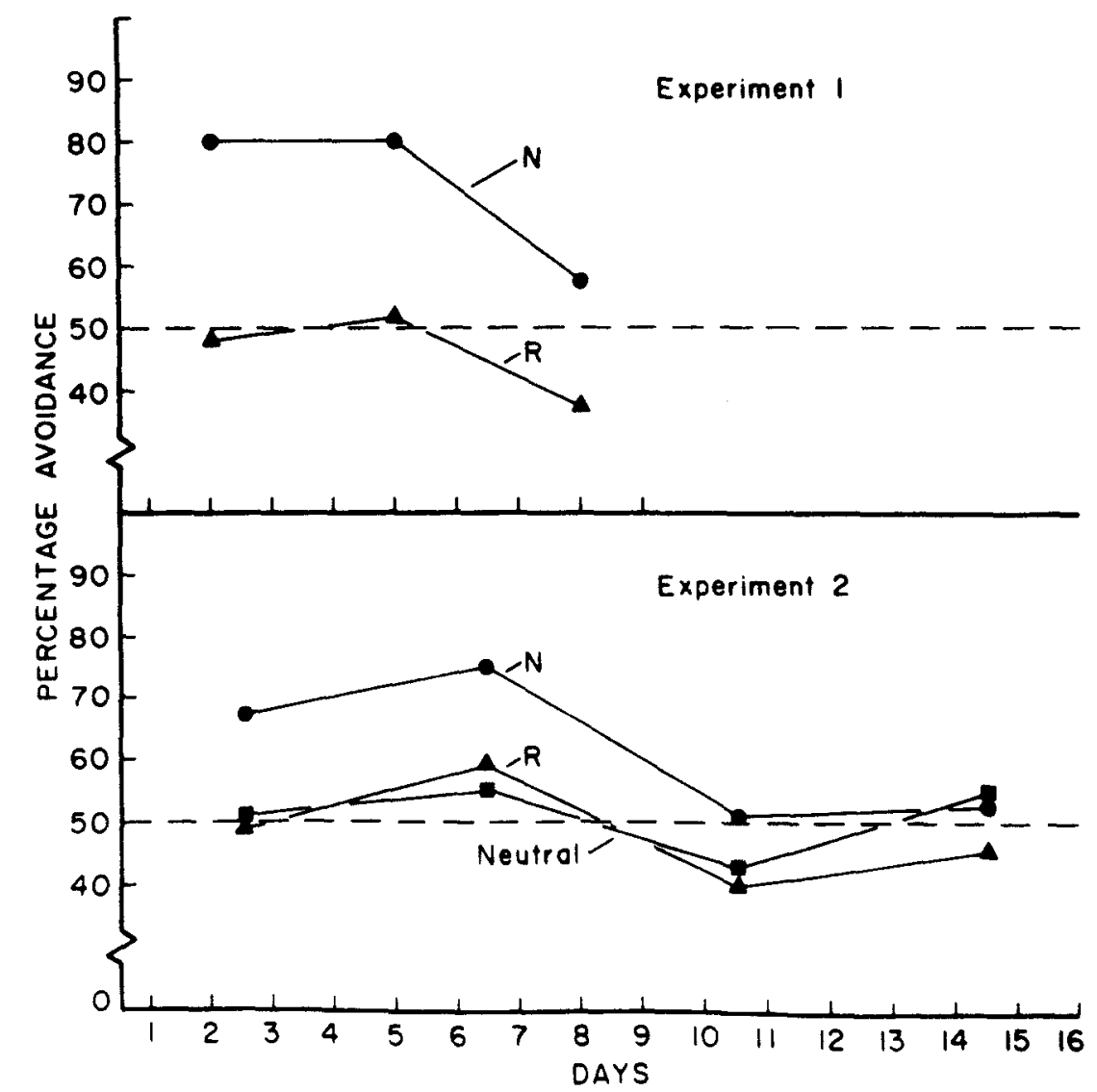

Fig. 1. Mean percentage of trials on which odor of nonreward $(\mathrm{N})$, odor of reward (R), and neutral odor were avoided as a function of blocks of 3 or 4 days 
laboratory suggests the possibility that subtle quantities of urine not ordinarily or readily observable may be involved.

Four other points are noteworthy. First, the aversiveness of the odor of nonreward seemed fairly mild, considering that avoidance behavior did not exceed $80 \%$ and that the odor stimulus was an accumulation from three Ss. ${ }^{1}$ Second, aversive odor was produced without requiring any substantial instrumental response in the odorant Ss, which is consonant with the inference that frustration can be evoked even though goal events are not contingent on any response save the act of consumption (Daly, 1969). Third, aversion of odor of frustrative nonreward appeared early in training. Indeed, data from Day 1 suggest that frustration odor appeared after two to four rewarded experiences of the type given here. Thus, frustration in the rat may occur after less training than commonly assumed; this conclusion agrees with that reached by Brooks (1969) on the basis of speed of escape from the locus of nonreward.

Finally, avoidance of nonreward diminished after 48-64 placements of odorant Ss (12-16 experiences of nonreward by experimental Ss) and was entirely absent during Placements 71-96 in Experiment 2. Clearly, this disappearance of avoidance behavior could be attributable to (1) a decrease in the quantity of frustration odor on later trials, i.e., an adaptation to frustrative nonreward by odorant $\mathrm{Ss}$, or (2) an adaptation to the odor by experimental Ss. Although the former is suggested by the casual observation that the extreme agitation of odorant Ss on early nonrewarded trials diminished somewhat later in training, other data from our laboratory point to the latter. That is, in four runway studies, differential responsivity to odor remained undiminished after 96 , 104 , or 144 trials of odorant Ss. Even more convincing, in a study highly similar to the present one, involving placed odorant Ss and utilizing the same apparatus, rats sustained a discrimination based on odor of nonreward throughout the 84 trials of the experiment (Morrison \& Ludvigson, 1970).

\section{REFERENCES \\ AMSEL, A. The role of frustrative nonreward in noncontinuous reward situations. Psychological Bulletin, 1958, $55,102-119$. \\ AMSEL, A., HUG. J. J., \& SURRIDGE. C. T. Subject-to-subject trial sequence, odor trails, and patterning at 24-h ITI. Psychonomic Science, 1969, 15, 119-120. \\ BROOKS, C. I. Frustration to nonreward following limited reward experience. Journal of Experimental Psychology. $1969,81,403-405$.}

DALY, H. B. Is instrumental responding necessary for nonreward following reward to be frustrating? Journal of Experimental Psychology, 1969, 80, 186.

DAVIS, S. F., \& LUDVIGSON, H. W. The "depression effect" and the problem of odor control. Psychonomic Science, $1969,14,193-194$.

FELLOWS, B. J. Chance stimulus sequences for discrimination tasks. Psychological
Bulletin, 1967, 67, 87-92.

LUDVIGSON, H. W. Runway behavior of the rat as a function of intersubject reward contingencies and constancy of daily reward schedule. Psychonomic Science, $1969,15,41-43$.

LUDVIGSON, H. W. Odor effects from delayed reward in rats. Paper presented at the meetings of Psychonomic Society. San Antonio, Texas, 1970.

LUDVIGSON, H. W.. \& SYTSMA, D. The sweet smell of success: Apparent double alternation in the rat. Psychonomic Science, 1967, 9,283-284.

McHOSE, J $H$. Patterned running as a function of the sequence of trial administration. Psychonomic Science, 1967, 9, 281-282.

MCHOSE, J, H JACOBY, L, L \& MEYER, P. A. Extinction as a function of number of reinforced trials and squad composition. Psychonomic Science, 1967, 9, 401-402.

McHOSE, J. H \& LUDVIGSON, H. W. Differential conditioning with nondifferential reinforcement. Psychonomic Science, 1966,6, 485-486.

MORRISON, R. R. \& LUDVIGSON, H. W Diserimination by rats of conspecific odors of reward and nonreward. Seience, $1970,167,904-905$

PRATT, L. K., \& LUDVIGSON, H. W. The role of odor in latent extinction. Psychonomic Science, 1970, 20, 189-190.

SEAGO, J. D., LUDVIGSON, H. W.. \& REMLEY, N. R. Effects of anosmia on apparent double alternation in the rat. Journal of Comparative \& Physiologica Psychology, 1970, 71, 435-442.

VALENTA, J. G., \& RIGBY, M. K Discrimination of the odor of stressed rats. Science, 1968, 161, 599-601.

WASSERMAN, E. A., \& JENSEN, D. D. Olfactory stimuli and the "pseudo-extinction" effect. Science, $1969,166,1307-1309$ NOTE

1. Evidence for the fact that odor does indeed accumulate has been repeatedly found in our laboratory, though reported in published form only once (Seago et al, 1970). 